
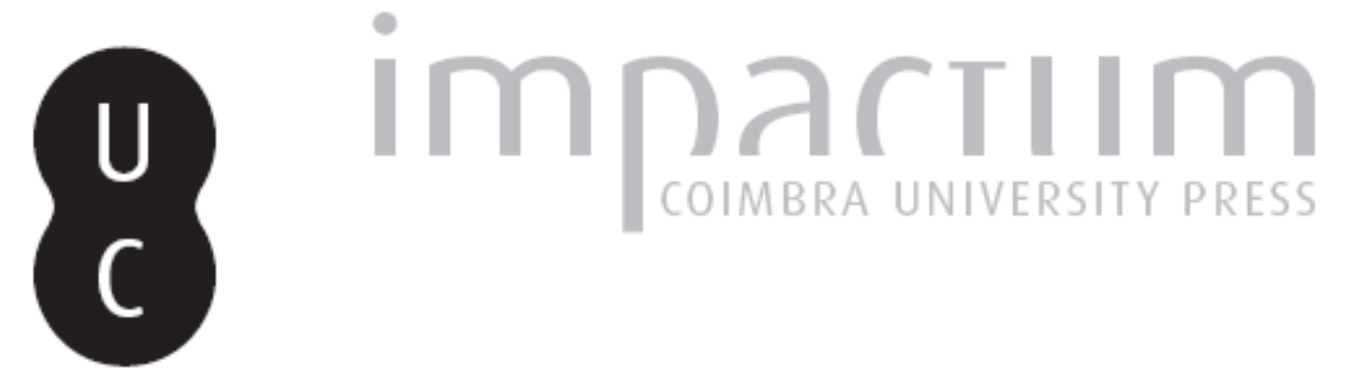

\title{
Universidade do Minho
}

\section{Autor(es): Ducrocchi, Emanuele}

Publicado por: Imprensa da Universidade de Coimbra

URL persistente:

URl:http://hdl.handle.net/10316.2/42523

DOI:

DOI:https://doi.org/10.14195/0870-8584_5_10

Accessed : $\quad$ 26-Apr-2023 10:57:32

A navegação consulta e descarregamento dos títulos inseridos nas Bibliotecas Digitais UC Digitalis, UC Pombalina e UC Impactum, pressupõem a aceitação plena e sem reservas dos Termos e Condições de Uso destas Bibliotecas Digitais, disponíveis em https://digitalis.uc.pt/pt-pt/termos.

Conforme exposto nos referidos Termos e Condições de Uso, o descarregamento de títulos de acesso restrito requer uma licença válida de autorização devendo o utilizador aceder ao(s) documento(s) a partir de um endereço de IP da instituição detentora da supramencionada licença.

Ao utilizador é apenas permitido o descarregamento para uso pessoal, pelo que o emprego do(s) título(s) descarregado(s) para outro fim, designadamente comercial, carece de autorização do respetivo autor ou editor da obra.

Na medida em que todas as obras da UC Digitalis se encontram protegidas pelo Código do Direito de Autor e Direitos Conexos e demais legislação aplicável, toda a cópia, parcial ou total, deste documento, nos casos em que é legalmente admitida, deverá conter ou fazer-se acompanhar por este aviso.

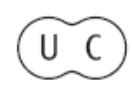




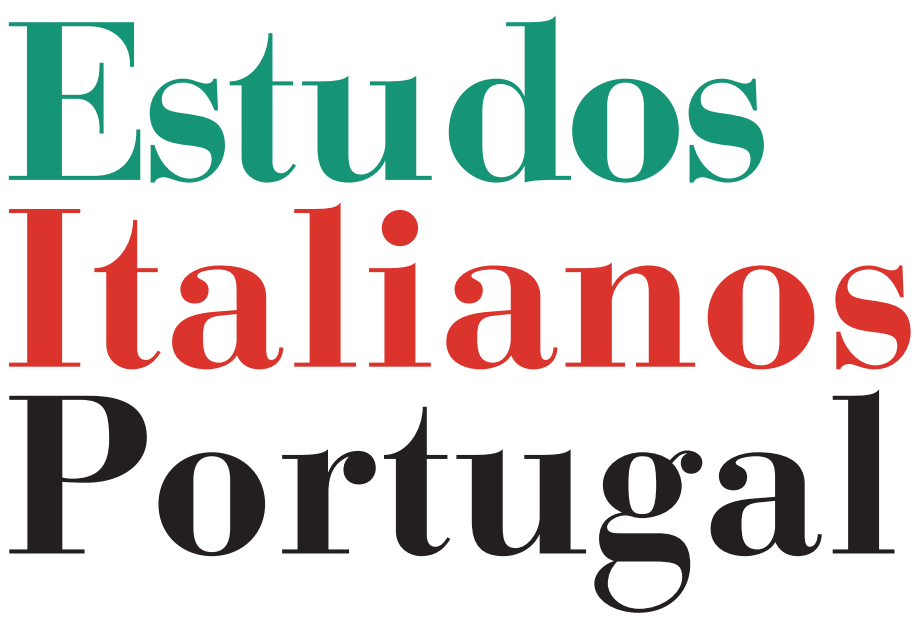

Instituto

Italiano

de Cultura

de Lisboa

Nova Série

$\mathrm{N}^{\mathbf{0}} 5$ 


\title{
UNIVERSIDADE DO MINHO
}

\author{
EMANuele Ducrocchi ${ }^{\star}$
}

L'Universidade do Minho (UM) è un'istituzione relativamente recente nel panorama universitario portoghese, essendo stata fondata nel 1973 ed avendo iniziato la sua attività nell'anno accademico 1975/1976.

Si è da sempre caratterizzata per la sua ampia offerta nel campo dell'insegnamento delle lingue straniere attraverso l'organizzazione di Cursos Livres, aperti cioè alla partecipazione di chiunque desideri imparare una lingua straniera. Ed è proprio attraverso questi corsi che la lingua italiana ha cominciato ad essere insegnata all'UM all'inizio degli anni '90, essendo da sempre una delle lingue più richieste.

L'insegnamento della lingua italiana a livello di Corsi di Laurea è iniziato nell'anno accademico 1999/2000 con il Corso di Laurea in Línguas Estrangeiras Aplicadas (attualmente Línguas Aplicadas) e da allora è sempre continuato, registrando anche quest'anno una partecipazione elevata di studenti (per maggiori informazioni su questo e

* Lettore di Italiano all'Universidade do Minho. Nato a Milano nel 1952, si è laureato in Economia Politica all'Università Bocconi di Milano. Ha maturato una esperienza nel campo dell'internazionalizzazione d'impresa e della formazione di quadri aziendali. Risiede da dieci anni in Portogallo, dove, oltre all'attività di docenza all'Universidade do Minho, svolge attività di formazione quadri (italiano commerciale ed italiano settoriale applicato alle attività produttive ed alle professioni). 
sugli altri Corsi di Laurea citati in questo articolo vedere http://www.ilch.uminho.pt). Gli studenti di questo corso possono scegliere l'italiano negli ultimi quattro semestri. Le altre lingue opzionali sono: tedesco, francese, inglese, spagnolo, russo, arabo.

Successivamente l'insegnamento dell'Italiano si è esteso con l'introduzione del corso di laurea in Línguas e Literaturas Europeias, in cui l'Italiano è insegnato sempre come lingua opzionale. In questo corso, il programma di lingua italiana include anche elementi di letteratura italiana. L'Italiano è insegnato, inoltre, nel Corso di Laurea in Musica e possono studiarlo, attraverso apposite opzioni curriculari, anche gli studenti dei Corsi di Laurea in Relações Internacionais e Negócios Internacionais.

A livello di mestrado l'italiano è inserito in quello di Tradução e Comunicação Multilingue, in funzione dall'anno accademico 2009/2010. L'obiettivo è quello di permettere agli studenti di sviluppare e consolidare quanto appreso nei precedenti tre anni, in modo da ottimizzare le loro capacità di tradurre e interpretare in lingua italiana.

L'insegnamento della lingua italiana é inquadrato nel Departamento de Estudos Românicos, diretto dalla prof.ssa Maria Rosário Girão Ribeiro Santos, dipartimento che a sua volta fa parte dell'Instituto de Letras e Ciências Humanas, presieduto dalla prof.ssa Maria Eduarda Bicudo Azeredo Keating.

Per quanto riguarda le prospettive future dell'insegnamento della lingua e della cultura italiane all' UM, la più immediata ha a che vedere con l'avvio del nuovo corso di laurea denominato Estudos Culturais. Si tratta di un nuovo corso di laurea e anche qui gli studenti avranno la possibilità di scegliere l'Italiano come lingua opzionale.

Come detto, lo sviluppo iniziale dell'insegnamento della lingua italiana all'UM è passato attraverso i Cursos Livres, che costituiscono tuttora un punto di forza dell'università. 
Nel corso degli anni, i corsi liberi d'italiano hanno sempre visto una consistente partecipazione e si punta ora ad un forte incremento dell'offerta.

Ciò è favorito dalla recente costituzione all'interno dell'Instituto de Letras e Ciências Humanas di BabeliUM - Centro de Línguas, che gestisce ora tutte le attività connesse ai corsi liberi all'interno dell'Università e l'organizzazione di corsi di lingue all'esterno, anche in partnership con entità pubbliche e private. Questa nuova struttura consentirà un miglior coordinamento ed una maggiore offerta nel campo dei corsi liberi, così come la sperimentazione di nuove forme d'insegnamento delle lingue (per maggiori informazioni su BabeliUM, vedere http://www.ilch.uminho.pt).

Per la prima volta, l'estate scorsa si è svolto all'UM un corso intensivo d'Italiano, che ha registrato un ampio successo e ha visto la partecipazione di studenti portoghesi e brasiliani. Per i prossimi anni l'Area Italiano ha predisposto una programmazione annuale dei corsi liberi d'Italiano che prevede un'offerta sempre più ampia. Tali corsi permetteranno agli studenti di arrivare fino ai livelli intermedi intensivi del Quadro Comune Europeo di Riferimento per le Lingue e sono previsti inoltre corsi specifici per il mondo del lavoro e dell'impresa, denominati “Italiano per Lavorare". L'offerta dei corsi d'Italiano non riguarderà solo il campus universitario di Gualtar (Braga) dell'UM ma anche quello di Azurém (Guimarães). In questi due campus universitari si svolge tutta l'attività accademica dell'UM.

In conclusione, possiamo dire che l'UM è attualmente uno dei principali centri di diffusione della lingua e della cultura italiane in Portogallo a livello universitario. 